\title{
Design of the LED Flexible Automation Assembly Line Structure
}

\author{
Shuai Li, Yao Dong and Lilan Liu* \\ Shanghai Key Lab of Intelligent Manufacturing and Robotics \\ Shanghai University \\ Shanghai, China \\ 1smichaelly@163.com,281406178@qq.com, lancy@shu.edu.cn
}

\begin{abstract}
With the development of LED technology, LED lamps have been widely used in many fields because of its significant characteristics such as environment friendly, high efficiency and energy saving. As the LED lighting market competition is fierce, the production efficiency is one of the most important factor considered by companies. This paper presents an LED lamps flexible automated assembly line. It can assembly different power LED bulb, tube lamps and spotlight at the same time. The assembly type can be adjusted according to the order form to improve the production efficiency.
\end{abstract}

Keywords-LED lamps; flexible assembly line; automated assembly line

\section{INTRODUCTION}

Light emitting diode (LED) is a kind of semiconductor devices converting electric energy into visible light [1]. With the development of LED technology, LED lamps as the fourth lamps after incandescent lamp, fluorescent lamp, high intensity discharge (HID) lamp has been widely used in many fields such as desk lamp, indoor and outdoor lighting, landscape lighting, street lamps, chandeliers, studio lamps, auto lamps, lanterns etc., because of its significant characteristics such as environment protection, high efficient and energy saving [2]. At present, the assembly of LED lamps is always a manual process. A few manufacturers adopt semi-automatic assembly. At the same time, assembly lamp type is unitary; it cannot realize different lamps mixed assembly. Assembly has low efficiency and high cost. This paper presents a flexible automation assembly line with LED bulb, tube lamps and spotlight. The flexible assembly line as a product of the industrial 4.0 is the key development direction in recent years [3]. With the development of economy, the needs of users change faster and faster, in order to meet the needs of users, Manufacturing enterprises have to change the production type to multi-variety. American National Standards Institute put forward five layer of CIMS system structure of the reference model including enterprise, workshop layer, cell layer, workstations and equipment layer. Cell layer, workstations and equipment layer. Constitutes the flexible manufacturing system (FMS) [4]. It responsible for the implementation of the complete production process and product physical transformation and become the basic cell of modern enterprise's production. Although owing to the nature of the enterprise production, there are many types of manufacturing; FMS has the characteristic of the flexible production will not change. Flexible assembly line is a new

Supported by Shanghai Economic and Information Technology Commission-funded projects No.15X1-1-26 assembly line that based on the traditional assembly line and brings in flexible manufacturing technology which enables the traditional line to have a new feature about flexible production. It can produce low cost, high quality and varieties of products in a short period. In this paper, the flexible mainly refers to the flexible process: system can determine the corresponding technological process according to the variation of the processing object or the change of raw materials; flexible production capacity: when production change, the system can respond in a timely manner and economic running; products flexible: can produce different types of products at the same time.

\section{ASSEMBLy PROCESS PLANNING}

A product is often composed of many parts. Assembly is the process to connect each part according to certain order and technology becoming complete mechanical products and realize the function of the product design [5]. Assembly is the last stage of the necessary product manufacturing. The quality of the final product is guaranteed and tested by assembling (from product design, parts manufacturing to product assembly). Therefore, the assembly is the key process to product quality. Formulate reasonable assembly sequence has significance to improve assembly efficiency, and ensure product quality. The assembly line is to complete the LED bulb, tube lamps and spotlight assembly. To complete the process planning must first learn more about the structure of the product and formulate assembly processes according to the product structure and assembly sequence. Three kinds of lamp structure are listed as follows:

LED bulb: Lampshade, PCB board, trays, plastic coated aluminum, the lamp capsule, nails, screws, power board.

tube lamps: PCB board, shell, translucent panels, end caps, screws, pallets, power board.

spotlight: Shell, lamp holder, screws, lamp cover, COB module, lens, power board.

Each part of the lamp installation process can be divided into several. To ensure the efficient organization of the assembly, the product can be divided into several independent assemblies mounting unit. Assemble the parts into the unit then turn to the finished products. By analyzing the structure of each lamp, mounting unit can be summed up as follows: Light plate board install, power panels install, lamp housing install, transparent mirror install. And besides it, there is a lighting test to ensure the quality. According to the requirements of the different 


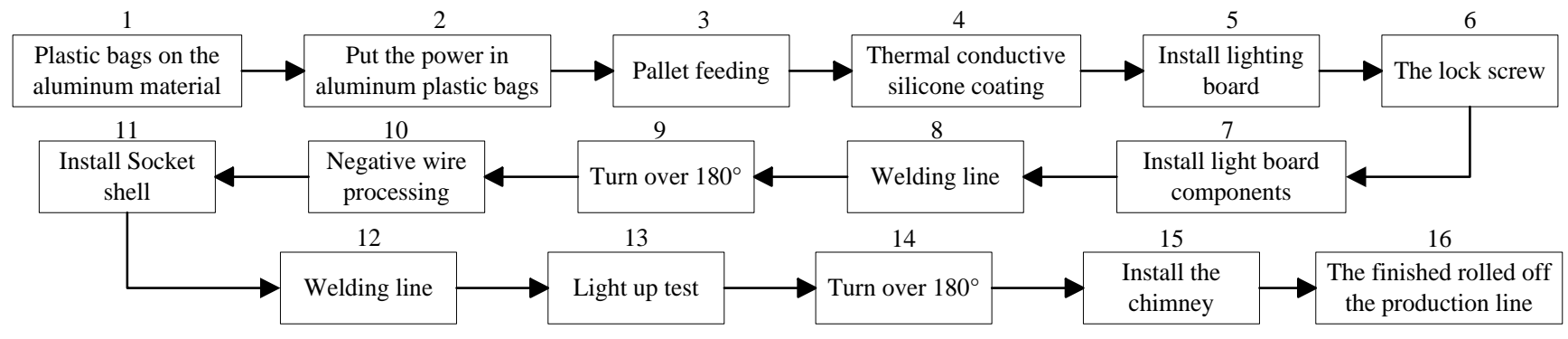

Fig. 1. The LED bulb lamp assembly process

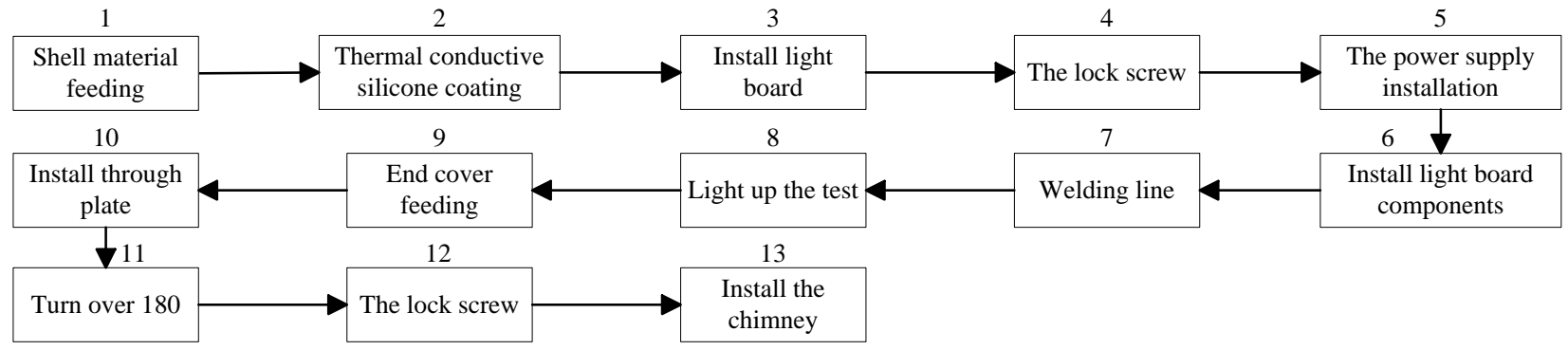

Fig. 2. The tube lamp assembly process

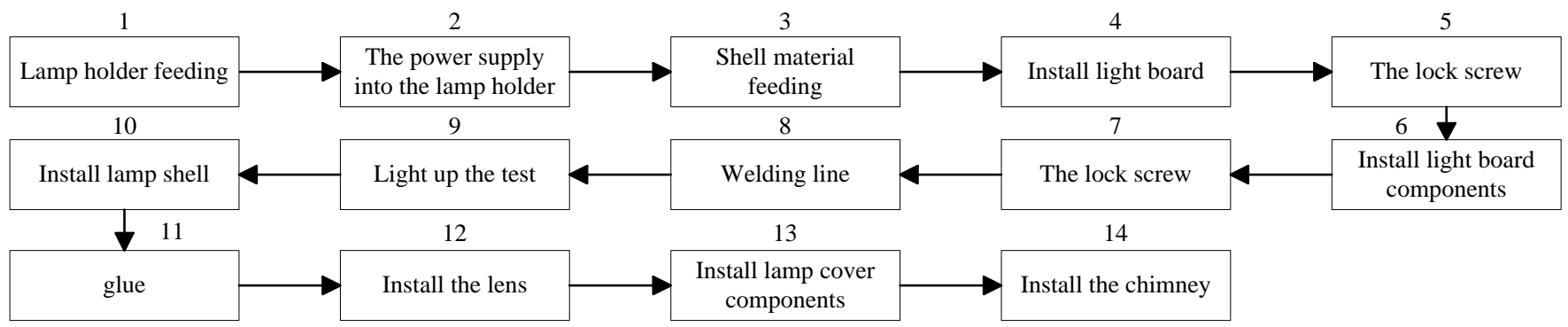

Fig. 3. The spotlight assembly process

components of the structure, technical experience, test and assembly relationships determine the assembly process of each lamp was shown in Fig. 1-3

\section{DESIGN OF THE ASSEMBLY LINE}

\section{A. Production Takt}

Working eight hours a day, 365 days a year, the annual output is $1.5 \times 10^{6}$. The ideal production takt is:

$$
\mathrm{T}_{\mathrm{i}}=8 \times 365 \times 3600 /\left(1.5 \times 10^{6}\right)=7.008 \mathrm{~s}
$$

The production line cannot work at full due to feeding, abnormal shutdown, fault repair and other causes of downtime. So the production line load rate is generally selected $70 \%$ to $85 \%$. Take $75 \%$ load factor. Therefore, the actual production takt is:

$$
\mathrm{T}=7.008 \times 75 \%=5.25 \mathrm{~s}
$$

Per $5.25 \mathrm{~s}$ produce a bulb.

The takt of the assembly is equal to station rotating time add longest execution time [6]. The station rotating time is less than $0.8 \mathrm{~s}$. The control system distributes $1 \mathrm{~s}$, so it has $0.2 \mathrm{~s}$ to ensure the system stability. Station execution (preparation, assembly or test) time of less than $4.7 \mathrm{~s}$. That station execution time is the execution time of the material preparation, assembly and inspection required to complete within $4.7 \mathrm{~s}$. The station execution time set by control system is $5 \mathrm{~s}$, so there is $0.3 \mathrm{~s}$ of the safety time to ensure the stability of the system. Through preliminary research on the executive special machine used by the system, execution can generally be completed within $4.7 \mathrm{~s}$. The execution time can be reduced by process optimization and step subdivision, which can improve the production efficiency. The station flow time set by the system plus station execution time is equal to $6 \mathrm{~s}$, which is the ideal production rhythm of the assembly line.

\section{B. Assembly Line Form}

According to the job content and product takt, using a tree structure, tandem structure combination of parallel structure of assembly line form. It is constituted by the bus as well as branch. Belt conveyors (linear) transfer lamp parts between the workstation. The stainless steel mesh belt is used as the carrier, which is suitable for the process operation under different conditions. Its specific dimensions determined according to the spatial position. Computer management of assembly planning, material distribution, assembly production process tracking, production command scheduling, production line performance analysis, fault warning and other functions. The whole assembly line of machinery, control, pneumatic and other systems using 
modular structure is composed of distribution, assembly, testing and other technology systems to achieve efficient production automation.

\section{Design of Workstation}

The number of stations included on each workstation is determined by the layout section. Three different types at most of lamps assembled in this workstation at the same time. So each station has to achieve at most three different types of lighting fixture. This workstation concludes fixture, rotating disk, turntable fixture, indexers and work base. Indexer is installed on the work base connecting to the rotating disk. Each turntable fixture concludes three fixtures. They were LED bulb part's fixture, tube slam part's fixture and spotlight part's fixture. When the part of one type of lamp put into the fixture, the turntable fixture rotating and putting another lamp's part into fixture. This kind of design can meet requirements that at most three different types of lamps assembly at the same time. The two kinds of workstation diagram were shown in Fig.4.

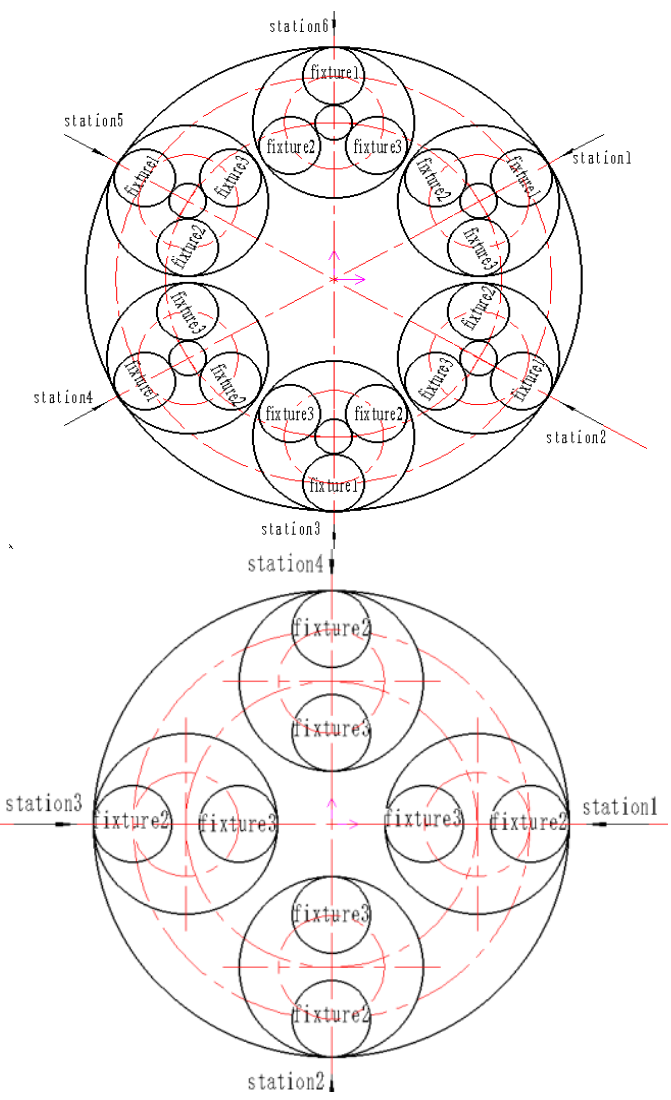

Fig. 4. Two kinds of workstation structure

\section{DESIGN OF ASSEMBLY LINE LAYOUT}

\section{A. The Overall Layout of the Assembly Line}

At present, there are two structures about production line: the layout based on the rotary table with multiple ring and layout based on the whole ring of flexible logistics trolley. With respect to the layout based on the whole ring of flexible logistics trolley [7], the advantages of layout based on the rotary table with multiple rings are high takt, low cost, without additional targeting methods and cam splitter itself can ensure positioning accuracy. But the disadvantage is that more compact layout and space arrangement is more intense. Considered factors about product rhythm, cost and complexity and so on, the layout of the production line is based on the multi ring layout of the rotary table[8]. Assembly line made up of 6 workstations, a workstation station within annular arrangement, and the overall layout of the assembly line as shown in Fig.5. The advantage of this arrangement is that:

a. Product appearance is small, weight is light, and the production line should be arranged in a table form;

b .Layout of the ring structure is compact and saving space, meanwhile the operating space is easy to encapsulation.

\section{B. Layout of Workstation}

According to Fig. 4, the assembly line has six stations, which are LED bulbs, tube lamps and spotlights process. Referring the flowchart, it is concluded that LED bulbs has 16 processes, tube lamps have 13 processes and spotlight has 15 processes. Quantified it into a mathematical model can be seen in Fig. 5. By the mathematical model diagram can be drawn three kinds of lights have the common part of the process. In the planning process, it is divided into several units. The common part of the process is a unit. So we put the common processes in the same workstation. So we get six workstations. As shown in Fig. 6, each color represents a workstation. The entire production line is divided into six workstations to design a modular production line to increase production line flexibility and save space.

Workstation1: Three kinds of light source component assembly. It includes five processes as following: Shell material feeding, coated thermal grease, the light source plate feeding, lock screw and put the light source component on the conveyor belt.

Workstation2: Two kinds of power component assembly. It includes three processes as following: Power feeding, plastic clad and lamp holder feeding put the power component on the conveyor belt.

Workstation3: Light source components and power component assembly. It includes six processes as following: The wires through the light board, bonding wire, put the LED bulb on conveyor belt to station six, lighting test, lock screw and put the light source components and power component on the belt.

Workstation4: The transparent plate assembly. It includes four processes as following: lamp cover feeding, gumming, transparent plate feeding put the transparent plate assembly on the conveyor belt.

Workstation5: Optoelectronic components and optical transmission component assembly. It includes four processes as following: optoelectronic components and optical transmission component placed in the fixture lock screw, tube lamps offline, and spotlight offline.

Workstation6: LED bulb Optoelectronic components assembly. It includes seven processes as following: optoelectronic components placed in the fixture, deal with the wire, bulb lamp holder feeding, riveting, welding, lighting test, put the component on the conveyor belt. 


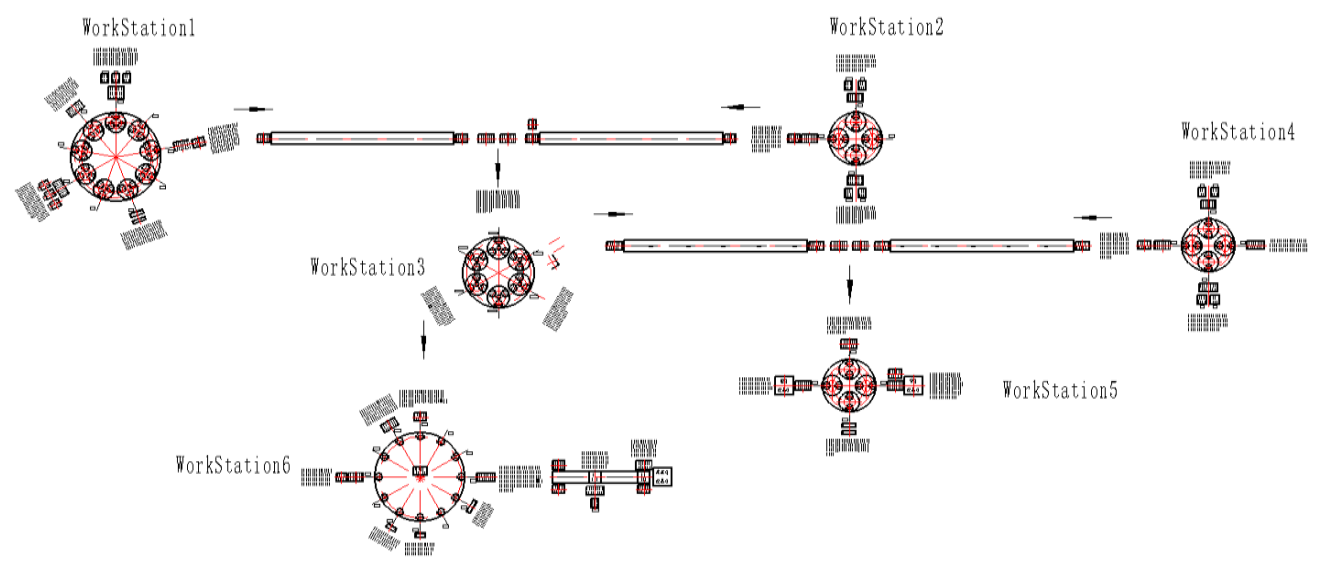

Fig. 5. Overall layout of the assembly line

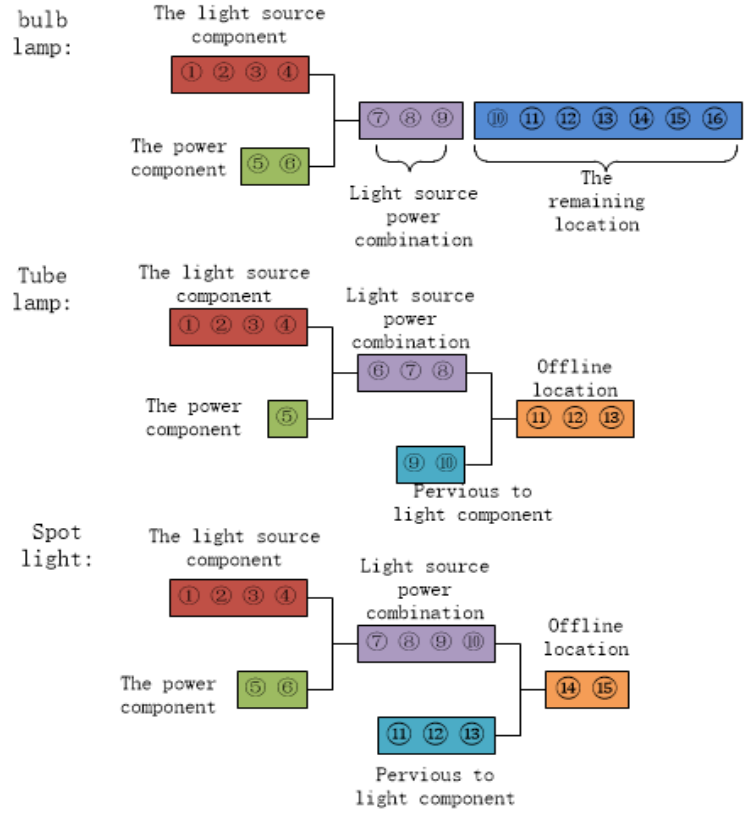

Fig. 6. Process quantization model

The layout of the workstation to consider the following points:

(1) Modular design, each workstation performing a specific function, easy to debug (first stand-alone debugging, and then line joint debugging;

(2) Each workstation can output a relatively complete component to facilitate the storage of semi-finished products and artificial sampling;

(3) The fixture on the working table must be uniform, the assembly process involves two $180^{\circ}$ workpiece attitude flipped, which will directly lead to the change of the fixture. Will design two flips between two workstations can be made fixtures on each workstation unity;

(4) Cutting stock in each workstation at the same time for product testing and sorting.

\section{CONCLUSIONS}

This paper designs a flexible automatic assembly line of
LED lamp. The assembly line can complete the fabrication of three different types of lamps in different power which are the LED bulbs, tube lights and spotlights. The layout design of Assembly line is the emphasis of this design, whether the overall layout of the assembly line is reasonable, determines whether the movement of the actuator will interfere, which affects the realization of the system assembly function directly. We analysis the product structure first. Secondly, determine assembly process flow through product structure and assembly sequence. Then design the takt of the assembly line, assembly line form as well as workstation structure. Finally, determine the layout of assembly line, in which determine the overall layout of the form, through the quantitative process to establish mathematical models, the process is divided into the number of units to determine the number of workstations and the distribution of the station. The design of this assembly line dramatically increases the efficiency of production of LED lights and saving labor costs.

\section{ACKNOWLEDGMENT}

This paper is supported by the mentors and doctoral student in Shanghai University.

\section{REFERENCE}

[1] Hui S.S, Qin Y.X. A general photo-electro-thermal theory for light emitting diode (LED) systems [J]. IEEE Transactions on Power Electronics. 2009, 24(8): 1967-1976.

[2] Linhua Ye, Song Li. Growth and characteristics of $\mathrm{Ce}^{3+}$ ions-doped YAG single Crystal optical fibers for LED white light [J]. Sources.GuangXue XueBao/Acta Optica Sinica. 2009, 29(SUPPL): 169-171.

[3] Jordan W C, Graves S T. Principles on the benefits of manufacturing process flexibility [J]. Management Science, 1995, 41: 577 594.

[4] Xian-kui Wang. CHEN Hong-xia. Mechanical manufacture technology [M]. Beijing: Mechanical Technology Press, 2010.

[5] JEFFERY. Automatic assembly and design for products [M]. Beijing: Mechanical Technology

[6] Liu Changyong, Application and research about auto parts flexible assembly system, Chinese Academy of Sciences, 2011.

[7] Jiang Yan, Xiangfeng Li, Dunwen Zuo. Simulation Research on stochastic and mixed assembly line[J]. Machine Building \& Automation, 2011, (1): 119--122.

[8] YowL, Matheson L A.Sequencing mixed model assembly lines with genetic algorithms. Computers and Industrial Engineering . 1996] 